\title{
Forensic opinion in questioned document based on scientific techniques
}

\author{
Reeta R Gupta \\ Senior Scientific Officer-Cum-Assistant Chemical Examiner to the Government of India, Central Forensic Science Laboratory, \\ Central Bureau of Investigation, CGO Complex, Lodhi Road, New Delhi, India
}

*Corresponding Author:

Email: reetacbi@gmail.com

\begin{abstract}
The current scenario of criminal activities has rapidly changed due to excessive use of internet facility through computer. The present trend in forensic science education and research is emphasized towards quality research in order to standardized methods and techniques to solve critical criminal cases. Document examiners always play an important role in criminal justice system, however many at times they are often encountered with number of random questions which really do not relate with the actual matter, and they are also forced to give answer during court testimony. The role of forensic document examiner while giving any opinion becomes more significant as they produce detailed scientific evidence which is better referred to as forensic evidence based on scientific principles and methodology, presented to convince the court in favour of justice.
\end{abstract}

Key words: Forensic Examination, Criminal Justice System, credibility.

\section{Introduction}

Today, we are living in the world of digital era and thus we cannot imagine life without any digital equipment. Every second we are facing new type of problems related to criminal incidents happening around us on a daily basis due to utilization of innovative methods by antisocial elements. The crime rate shows an increasing trend from last two to three decades. Crime rate is defined as the number of crime per $1,00,000$ population. It is generally taken as a realistic indicator of crime while the rate of crime is to be taken in record. Now, it is a big challenge to solve various types of cases with the use of novel scientific techniques and adaptation of advanced research methodology in the field of questioned document examination. So it is an urgent need of hour in the changing scenario of criminal activities and solving these complex cases, the forensic scientist should be equipped with more advanced and innovative techniques. The present trend in forensic science education and research is emphasized towards quality research in order to standardized methods and techniques. In India, most of the forensic laboratories are overburdened with huge number of cases and high pendency of the number of cases is due to many reasons such as shortage of staff, lack of advanced facilities and adequate policies of advanced training as well as research and development programs. Scientific evidence which is an acceptable base in court of law as well as in scientific community is also referred to as forensic evidence. Forensic evidence is based on the application of scientific principles along with the laboratory techniques with involvement of various other branches of natural Sciences. The purpose of application of novel scientific theory is to assist court to arrive at correct decision on the basis of judicious scientific opinion given by the expert, not only to demonstrate the technological advancement and innovative scientific methods. However it is not very easy to conduct experiments with the original case by using only innovative scientific technique because of various reasons, especially in questioned document examination mostly preference is given to nondestructive scientific techniques. The main prominence in questioned document examination is to keep the integrity of exhibits as in its original form. Document examiners always play an important role in multidisciplinary functions in criminal justice system, however many at times they face number of random questions which really do not relate with the actual matter, and they are also forced to give answer. The Forensic evidence plays a vital role in criminal investigation and in solving variety of disputes either civil or criminal. The current scenario of criminal activities has rapidly changed due to excessive use of internet facility through computer. Digital forensics is relatively a new forensic discipline, concerned with the use of computers and the investigation of cybercrime. In this digital world, examination of computer printouts and machine generated documents are also enhancing on day to day basis. Machine generated document examination is very difficult to proof scientifically, in case of cheating and forgery while with linking of cases through modus operandi that leads into criminal justice. The identification of particular criminal/criminal activities can be established by application of scientific techniques and principles of forensic science. Recently, new researches and advancement in science has taken place, hence the same can be effectively applied to prove the most of the complicated criminal cases with standard operating procedures. In order to produce reliable scientific proof of evidence for a competent Forensic expert, application of effective and precise 
tools for criminal investigation is now the call of the hour and thus the role of the forensic scientist becomes more significant in the modern age of science and technology. The questioned document examiner while expressing his/her opinion it is must to explain complex questions with reasonable scientific answers, with adhering to the self-explanatory scientific report, which become more effective in producing detailed scientific evidence in the form of opinion so as to convince the court.

\section{Challenges in Questioned Document Examination}

Recently, all-in-one machines for printing and photocopying the document is in more fashion. The examination of photocopied document is required in varieties of cases which thrown as a big challenge in front of the forensic document expert to solve such criminal cases on the basis of submitted photocopied document for examination in absence of original one. Another aspect of the same issue is how to address the limitation of the field. Expressing opinion on age of document is also a big issue for forensic document experts. In certain cases, relative age of document can only be possible to establish by analyzing the chronical data which is available for examination. This is critically a serious situation for forensic scientist as sometime they find themselves not enough comfortable with giving findings during the examination because of limited material and source of factual information in absence of original one. In such circumstances, the forensic document expert needs to take judicious decision for the acceptance of these cases for conducting the examination of such photocopied/reproduced documents because the credibility and authenticity of report is to be accepted in court of law, which is the biggest challenge before the forensic scientist. Being the central role of forensic scientist in criminal justice system, they must take concrete steps in conduction of research in various areas, such as, for machine generated document examination, utilization of automated computerized instrumental use in solving criminal cases. Mostly, in expert's decision making processes, observation notes are very important in which all the available significant characteristic features/scientific findings compiled thoroughly in between questioned and standard documents during comparison, sometimes due to limited material or in absence of similar comparable content conclusive opinion is not possible to frame. In such circumstances they can give only the observation note by explaining all detailed available data as a proof of evidence; however it is not very simple to say the fact and also it depends upon the decision of the expert by his/her own learning, experiences as well as expertise in the field, in what way he/she may express the opinion either conclusive or not. There is only a forensic Scientist who produces all the scientific date in the form of forensic evidence in the court of law, on the basic of which the judgment is being taken in favor of criminal justice System. Henceforth the forensic scientists are bearing a very big responsibility on their shoulders because the forensic evidence represented by them would lead to the justice. Scientific reports based on the forensic examination with application of appropriate methodology as well as accurate interpretation of all the proof the evidences in scientific manner in court by the competent expert can only boost the confidence of this field experts in the administration of criminal justice. It also helps to maintain the credibility and accountability of the experts as well as forensic community. How it can be made possible to achieved, is the big challenge in front of the forensic community. The discussion is focuses on choosing suitable methods and procedures, the role of the forensic scientist in accurate interpretation of data using standardized techniques with scientific temperament in favour of true value of justice. Sometimes challenges may involve the integrity of the Forensic laboratory by mean of seeking various questions. For example the laboratory may or may not be accredited. It might not be compliance with standard guidelines. The standard operating procedures for examination of forensic exhibits follows or not, the procedure adopted is available in laboratory manual or not. At the same time the technical challenges are also faced by the document expert, or how the experimental results are interpreted in court of law. How many standards are required for comparison of questioned document? As the document science is a branch of forensic science which continues to evolve like other branches. Now, more complex and informative testing methodologies are in process of innovation in various grey areas of questioned document field such as machine generated document analysis, relative age of document, examination of sequence of strokes, age of ink and paper analysis. However, the scientist in leading Central Forensic Science laboratory are focusing on application of valid novel method as per standard operating procedures for solving critical criminal cases.

\section{Conclusion}

Now a days, one of the important and comprehensive sources of information is digital world and anyone can be able to access these data for their desire purposes either by the criminals or by common person. The digital world is also changing the nature and shape of criminal activities because of which we as a common citizen are more vulnerable with these criminal activities. Forensic scientists are facing much more critical problems of criminal cases. The broad information is available which can be improperly utilized by antisocial element to conduct their criminal activities. Utilization of the novel techniques and adaptation of advanced research methodology in the field of questioned document examination is demand of the time in the changing scenario of criminal cases. 
With all these discussion, it can be summarized that more advance research would be required in future and preparation of chronical data base of the events of each and every incident of criminal activities is an urgent need of hour by utilization of recent methodology. Forensic science is applied Science, hence researchers, scientist and specialist of every field of natural science need to contribute their knowledge and expertise in this field to solve criminal cases as well as efficiently get updated with research and development work in the field of forensic science so as to meet the future challenges . The objective based research and development should be seriously required to emphasize in all areas in order to meet the present as well as future challenges with overcoming the limitation of questioned document field. Importance of forensic science services cannot be ignored at any cost because it always plays a vital role in administration of criminal justice system. The well experienced, qualified and skilled expert can perform better during court testimony in presentation of evidential data and would be able to contribute their important role in justice. The credibility of forensic experts will be maintained by their own valuable $\&$ reliable scientific report submitted after thorough forensic examination based on scientific principles with application of appropriate validated methods for their true value in justice. With the advent of advanced science and technology, the tactics and working of investigating authorities as well as understanding of common citizen with awareness of law and facts is also changing. Hence forensic experts may contribute their work courageously and pride themselves as independent finder of truth with application of innovative scientific methods.

\section{References}

1. Albert S. Osborn, The Problem of Proof, Essex Press, New York, NJ. 1926.

2. Albert S. Osborn Questioned Document Second Edition Body Printing Company, Albany, NY 1929.

3. Harrison, W. R., "Suspect documents- their scientific examination", Nelson-Hall. 1958.

4. Convey, J.V.P., Evidential Documents, Charles C. Thomas, Springfield, II. 1959.

5. Hardless, H. R. (1970), "Disputed documents examination \& fingerprint identification", Law book company.

6. Conway, J. V. P., "Evidential documents", Chales C Thomas publisher Ltd. 1978.

7. Ordway Hilton, Scientific Examination of Questioned Document, Revised Edition, CRC Press. 1993.

8. Wilson R Harrison (1997), Suspected Document: Their Scientific Examination, second Indian Reprint, Universal Law Publishing Co. Pvt. Ltd.

9. Huber, R. A. \& Headrick, A. M., "Handwriting identification- facts and fundamentals", CRC Press, Boca Roton, FL. 1999.

10. Morris, R. N., "Forensic handwriting identification: fundamental concepts and principles", Academic Press.

11. Morris R., Forensic Handwriting Identification, Fundamental Concepts and Principles, Academic Press, New York. 2000.

12. Levinson J., Questioned Document, A Lawyer's Handbook, academic Press, New York, 2001.

13. Ellen, D. "Scientific examination of documents- methods and techniques", 3rd edition, CRC Press- Taylor \& Francis group. 2006.

14. Forensic Handwriting Examination-A Definitive Guide. Reed Hayes. Reedwrite press, Honolulu, HI.2006.

15. Kelly, J. S. \& Lindblom, B. S. "Scientific examination of questioned documents", CRC Pres Taylor \& Francis group. 2006.

16. Koppenhaver, K. M. (2007), "Forensic document examination- principles and practice", Humana Press Inc.

17. Gupta R.R. "Importance of Handwriting Science in Court” J. For. Sci \& Crim. Invest. 2018:9(3).

18. Gupta R.R. "Challenges in Forensic Examination of Photocopied Document" Int J. For. Sci \& Tox. Res. 2018:3(1) 